\title{
0 Tribunal de Contas da União (TCU) e a gestão ambiental brasileira - experiência recente
}

Luiz Henrique Moraes de Lima*

\begin{abstract}
Resumo
A Constituição de 1988 ampliou a esfera de competência do Tribunal de Contas da União (TCU), assegurando-Ihe maior poder de atuação, inclusive na área ambiental. A partir de 1998, com a definição de sua estratégia de atuação nessa área, e de forma crescente, o TCU vem desempenhando um importante papel na avaliação das políticas ambientais públicas do governo federal. A realização de diversas auditorias operacionais em instituições e programas governamentais têm resultado em minuciosos diagnósticos e relevantes recomendações, no sentido de tornar mais efetivas as políticas públicas ambientais.

Este estudo descreve e comenta a evolução da fiscalização do TCU sobre a gestão ambiental brasileira nos últimos anos. Também é lembrada a atuação de entidades de fiscalização superiores de outros países na área ambiental. São analisados os critérios da estratégia de atuação ambiental do Tribuna de Contas, bem como as determinações e recomendações de algumas recentes deliberações envolvendo a gestão de recursos hídricos, o licenciamento ambiental e a avaliação ambiental estratégica. Este artigo procura relacionar a atuação do TCU na área ambiental com a busca por um controle preventivo, pedagógico e orientador da gestão pública, em substituição ao tradicional modelo de controle formalista e a posteriori. 0 artigo conclui que a atuação do tribunal é positiva para a sociedade, recomendando que seja ampliada.
\end{abstract}

Palavras-chave: Cadma; TCU; gestão ambiental pública; política ambiental.

\begin{abstract}
The 1988 Brazilian Constitution increased and strengthened the environmental mandate of the Tribunal de Contas da União - TCU, Brazilian Supreme Audit Institution. Since 1998, with the definition of its environmental strategy, TCU has been an increasingly important player on the assessment of federal government environmental policies. The execution of many operational audits in government institutions and programs has resulted in detailed diagnostics and relevant recommendations towards increasing the effectiveness of environmental public policies. The paper describes and comments the evolution of TCU's inspections in recent years over the environmental management in Brazil. Comments are made about the environmental performance of other countries' Supreme Audit Institutions. TCU's environmental strategy criteria are analyzed, as well as the determinations and recommendations of some recent decisions involving water resources management, environmental licensing and strategic environmental assessment. TCU's environmental performance is associated to the preventive, pedagogic and orienting model of control as opposed to the traditional a posteriori compliance model. To conclude, TCU's environmental action is assessed as positive for society and its intensification is recommended.
\end{abstract}

Key words: Cadma: TCU; environmental public management; environmental policy.

\section{Responsabilidade ambiental do TCU}

A Constituição de 1988 ampliou consideravelmente as atribuições do Tribunal de Contas da União. O Brasil vivia uma conjuntura política em que a maior parte da sociedade queria ampliar os espaços democráticos recém-conquistados e estabelecer mecanismos institucionais de controle do Estado. No cenário mundial, era o

\footnotetext{
* Luiz Henrique Moraes de Lima

Analista de Controle Externo do Tribunal de Contas da União. Doutorando em Planejamento Energético, PPE-COPPE-UFRJ. E-mail: luizhm@ @tcu.gov.br. Endereço: Praia do Flamengo, 386/102, Flamengo, Rio de Janeiro - R - 22210-030.
}

Artigo recebido em maio de 2005 e aceito para publicação em julho de 2005. 
momento em que questão ambiental emergia como um dos temas mais relevantes nas relações econômicas internacionais e nas políticas interna e externa de cada país. A conjunção dessas circunstâncias trouxe, pela primeira vez, a temática ambiental para o âmbito do controle externo da administração pública. Assim, a nova Carta dos brasileiros estabelece no caput de seu artigo 225 que:

"Todos têm direito ao meio ambiente ecologicamente equilibrado, bem de uso comum do povo e essencial à sadia qualidade de vida, impondo-se ao Poder Público e à coletividade o dever de defendêlo e preservá-lo para as presentes e futuras gerações."

Dessa forma, o meio ambiente ecologicamente equilibrado passa a ser considerado um patrimônio, cuja defesa e preservação - estratégicas para as atuais e futuras gerações - são de responsabilidade do poder público. No texto constitucional, igualmente merece destaque a definição de patrimônio nacional expressa no parágrafo $4^{\underline{0}}$ do mesmo artigo 225:

"A Floresta Amazônica brasileira, a Mata Atlântica, a Serra do Mar, o Pantanal Mato-Grossense e a Zona Costeira são patrimônio nacional, e sua utilização far-se-á, na forma da lei, dentro de condições que assegurem a preservação do meio ambiente, inclusive quanto ao uso dos recursos naturais."

Para Bandeira de Mello (1997), o conceito de bem público é aplicado a todos os bens pertencentes às pessoas jurídicas de direito público (União, estados, Distrito Federal, municípios e suas respectivas autarquias e fundações) e também àqueles que, embora não pertençam a nenhuma dessas pessoas jurídicas, estejam relacionados à prestação de um serviço público. Por domínio público entende-se o conjunto dos bens públicos, móveis e imóveis, classificados em: de uso comum, de uso especial e dominicais. No entanto, ao relacionar os bens quanto à sua natureza física, Bandeira de Mello os dividiu em duas categorias principais: os bens do domínio hídrico, incluindo os "potenciais de energia hidráulica", e os do domínio terrestre, do solo e do subsolo. De certa forma, essa classificação é incompleta, pois não considera situações como o ar puro, a paisagem preservada, a fauna, a flora e a biodiversidade, que inegavelmente são componentes de um meio ambiente ecologicamente equilibrado.

Assim, quando nos artigos 70 e seguintes da Constituição Federal é definido que o controle externo será feito pelo Tribunal de Contas da União, em auxílio ao Congresso Nacional, fica estabelecida a competência dessa corte na área ambiental. ${ }^{1}$

De fato, zelar por um "patrimônio nacional" como a floresta amazônica - ou pelo "bem de uso comum do povo", que é o meio ambiente "ecologicamente equilibrado" - passou a representar uma nova e desafiadora tarefa para a centenária instituição, criada pela primeira Constituição republicana sob a inspiração de Rui Barbosa.

Nesse contexto, as palavras-chave são "operacional" e "patrimonial". Como um patrimônio a ser protegido pela União, o meio ambiente passa a integrar o universo de bens nacionais cuja utilização, guarda, administração e conservação estão sujeitas ao controle externo. E uma vez que também se define como responsabilidade institucional do Tribunal de Contas da União a realização de inspeções e auditorias operacionais nas suas unidades jurisdicionadas e em todas as entidades que recebam recursos públicos federais, inclusive por convênios, acordos e outros instrumentos, é a gestão ambiental como um todo que será objeto de avaliação quanto à sua legalidade, legitimidade e economicidade (LIMA, 2001). Por conseguinte, compete ao TCU, no seu papel de guardião da legalidade, da economicidade e da eficácia na aplicação dos recursos públicos, zelar pela proteção ao meio ambiente e pelo respeito à legislação ambiental brasileira.

Recentemente, um ex-presidente do TCU afirmou que a atuação do tribunal poderia prevenir significativos prejuízos ao governo federal, como aqueles causados por multas pelo descumprimento da legislação ambiental ou pela responsabilidade civil objetiva de reparar danos ambientais causados a terceiros. Segundo esse ex-

\footnotetext{
O controle externo compreende a fiscalização contábil, financeira, orçamentária, operacional e patrimonial da União e das entidades da administração direta e indireta, quanto à legalidade, legitimidade, economicidade, aplicação das subvenções e renúncia de receitas.
} 
presidente, o tribunal poderia ainda prevenir prejuízos causados ao país, não apenas obrigando a recuperar o meio ambiente degradado por ação ou omissão de suas entidades, mas também evitando perdas financeiras decorrentes de limitações extra-alfandegárias impostas por outras nações à importação de produtos brasileiros, ou aquelas decorrentes de medidas punitivas pela inobservância de tratados ambientais internacionais pelo Brasil, ou, mesmo pela indisponibilidade de recursos naturais necessários às atividades produtivas (SANTOS, 1997).

\section{A dimensão ambiental da atividade fiscalizadora do TCU}

Pode ser vista sob vários aspectos. Antes de tudo, por um enfoque mais tradicional, verificando a legalidade, a economicidade e a eficácia da gestão dos órgãos diretamente vinculados ao Sistema Nacional de Meio Ambiente (Sisnama), especialmente o Instituto Brasileiro do Meio Ambiente e dos Recursos Naturais Renováveis (Ibama). É claro que a efetiva garantia dos princípios constitucionais relativos à proteção ambiental, bem como da aplicação das diretrizes da Política Nacional de Meio Ambiente, estão estreitamente vinculadas à adequada gestão dos recursos públicos por aqueles órgãos.

Em segundo lugar, ao fiscalizar entidades da administração direta e indireta cujas atividades causem significativo impacto ambiental - especialmente nas áreas energética e mineral, como Itaipu, Furnas, Eletronuclear, Petrobrás etc. - cabe ao TCU verificar o cumprimento da legislação ambiental. Não se pode atestar como regular o emprego de recursos públicos que venha a causar danos ao meio ambiente ou ameaçar a saúde e a segurança pública. Desse modo, estariam sendo avaliados os resultados das políticas ambientais implícitas nas políticas públicas setoriais (GLIGO, 1997).2 Associada a esse aspecto está a hipótese do Tribunal de Contas da União intervir - se a entidade federal foi multada por órgão ambiental estadual ou municipal por infringir as respectivas normas ambientais -, exigindo ações regressivas contra os dirigentes da entidade ou contra quem seja identificado como responsável pela ocorrência que traga prejuízo aos cofres públicos federais e ao meio ambiente nacional.

Ademais, na verificação das prestações de contas, ou durante auditoria, relativas aos recursos repassados a estados, ao Distrito Federal, a municípios, organizações não-governamentais (ONGs) e a outras entidades, o TCU deve assegurar-se de que a aplicação das verbas obedeceu ao estabelecido na legislação ambiental, tenha ou não o convênio ou instrumento congênere visado atividade ou projeto referente à proteção do meio ambiente.

Outro importante aspecto diz respeito aos financiamentos a empresas privadas pelos organismos oficiais de crédito e de fomento (Banco do Brasil - BB, Caixa Econômica Federal - CEF, Banco Nacional de Desenvolvimento Econômico e Social - BNDES, Banco da Amazônia - Basa, Financiadora de Estudos e Projetos - Finep etc.) bem como à renúncia de receitas pela concessão de incentivos fiscais. É papel do tribunal certificar-se de que tais mecanismos, que envolvem a aplicação de recursos públicos, não contribuam para a degradação do meio ambiente. 3 Aliás, o Decreto no 99.274/90 condicionou a concessão de incentivos ou de financiamento pelas entidades governamentais à comprovação do licenciamento ambiental. Portanto, cumpre ao controle externo verificar se tais condições estão sendo observadas.

Em seu estudo sobre as auditorias ambientais no âmbito do TCU, Lima (2001) classificou as várias espécies dessas auditorias, conforme resumido pelo quadro 1 .

\footnotetext{
${ }^{2}$ As políticas ambientais implícitas são os efeitos, geralmente negativos, sobre o meio ambiente, de decisões tomadas em outros segmentos de políticas públicas, como as que visam estimular certos setores produtivos, o fomento às exportações, a expansão das fronteiras de produção agropecuária etc. (GLIGO, 1997).

${ }^{3}$ Entre 1970 e 1985 foram concedidos US $\$ 700$ milhões em incentivos fiscais e créditos subsidiados a 950 projetos na Amazônia, dos quais 631 para abertura de novas áreas à pecuária. Entre 1978 e 1994, a área desmatada naquela região passou de $78 \mathrm{mil}$ para 470 mil km² (BRASIL, 1998).
} 


\begin{tabular}{ll}
\multicolumn{1}{c}{ Quadro 1 - Tipologia das auditorias } & ambientais no âmbito do controle externo \\
\hline TIPO & OBJETIVO \\
\hline Auditoria de orçamento ambiental & $\begin{array}{l}\text { Analisar a aplicação dos recursos alocados para } \\
\text { programas ambientais, oriundos de dotações } \\
\text { orçamentárias, de empréstimos ou doações } \\
\text { internacionais, ou da própria receita dos órgãos } \\
\text { ambientais. }\end{array}$ \\
\hline Auditoria de impactos ambientais & $\begin{array}{l}\text { Analisar o impacto causado ao meio ambiente pelas } \\
\text { atividades exercidas pelo Estado, diretamente ou por } \\
\text { concessões, permissões e autorizações. }\end{array}$ \\
\hline $\begin{array}{l}\text { Auditoria dos resultados das políticas } \\
\text { ambientais }\end{array}$ & $\begin{array}{l}\text { Analisar a eficiência das políticas públicas voltadas } \\
\text { para o meio ambiente }\end{array}$ \\
\hline Auditoria da fiscalização ambiental pública & $\begin{array}{l}\text { Analisar a eficiência da atuação do poder público } \\
\text { como fiscal do meio ambiente }\end{array}$ \\
\hline $\begin{array}{l}\text { Auditoria do cumprimento dos tratados } \\
\text { ambientais internacionais }\end{array}$ & $\begin{array}{l}\text { Analisar a adequada execução de tratados firmados } \\
\text { pelo Brasil }\end{array}$ \\
\hline & $\begin{array}{l}\text { Analisar a conformidade dos licenciamentos } \\
\text { concedidos para atividades potencialmente causadoras } \\
\text { de significativo impacto ambiental, bem como a }\end{array}$ \\
$\begin{array}{l}\text { Qualidade dos estudos de impacto ambiental e dos } \\
\text { relatórios de impacto ambiental. }\end{array}$ \\
\hline $\begin{array}{l}\text { Auditoria do impacto ambiental das políticas } \\
\text { fe incentivos fiscais, subsídios e } \\
\text { financiamentos concedidos por organismos }\end{array}$ & $\begin{array}{l}\text { Analisar o impacto ambiental das políticas de } \\
\text { incentivos fiscais, dos subsídios e dos financiamentos } \\
\text { concedidos por organismos oficiais de crédito. }\end{array}$ \\
\hline
\end{tabular}

Fonte: Lima (2001).

\section{Panorama internacional}

O Tribunal de Contas da União não está isolado na sua preocupação em exercer o controle externo também na área ambiental. A emergência desse tema como uma questão política maior no cenário internacional levou outras entidades fiscalizadoras superiores (EFSs) a desenvolverem instrumentos e métodos para a auditoria ambiental, segundo a legislação de seus respectivos países, destacando-se o Canadá, a Holanda, o Reino Unido e a Colômbia.

A International Organization of Supreme Audit Institutions (Intosai), que reúne cerca de 170 entidades fiscalizadoras superiores, estabeleceu em 1992 um grupo permanente de trabalho em auditoria ambiental, inicialmente presidido pela Corte Holandesa de Auditoria. Seus principais objetivos são: apoiar as entidades fiscalizadoras superiores - para uma melhor compreensão das questões relacionadas à auditoria ambiental - e promover o intercâmbio de informações e de experiências nesse campo, além de publicar diretrizes e outros materiais informativos para uso dessas entidades fiscalizadoras, incluindo sugestões de métodos para a realização das auditorias. Em 1995, o $15^{\circ}$ Congresso da Intosai, no Cairo, teve como um de seus principais temas as auditorias ambientais.

Um dos primeiros resultados da atuação do grupo permanente de trabalho formado em 1992 foi um documento sobre a cooperação entre entidades fiscalizadoras superiores de diferentes países em auditorias de tratados ambientais internacionais (INTOSAI, 1998).

Cabe registrar que, conforme a Declaração de Lima sobre diretrizes para auditorias, adotada no IX Congresso da Intosai, em Lima, em 1977, a auditoria não representa um fim em si mesma, mas um componente indispensável de um sistema regulador. O objetivo desse sistema é apontar os desvios dos padrões aceitáveis e as violações aos princípios de legalidade, eficiência, efetividade e economia da administração pública, o quanto antes, para que seja possível adotar ações corretivas em casos isolados, atribuir responsabilidades, obter compensações e implantar medidas para prevenir ou, no mínimo, dificultar, a ocorrência dessas falhas (INTOSAI, 1977). 
Outra relevante atividade do grupo permanente de trabalho da Intosai foi a elaboração, em 2001, de documento-guia para orientar as auditorias operacionais a partir de uma perspectiva ambientalista, incluindo a capacidade dos governos de monitorar o cumprimento da legislação ambiental, a performance dos programas ambientais, o impacto dos programas governamentais no meio ambiente, os sistemas de gerenciamento ambiental e a avaliação, pela ótica ambiental, das propostas de políticas e programas de governo.

Em 1995, o Office of the Auditor General, do Canadá, instituiu um Comissariado do Meio Ambiente e do Desenvolvimento Sustentável para examinar, da perspectiva do desenvolvimento sustentável, mudanças nos programas e nas políticas governamentais, bem como prover intercâmbio, monitoramento e estímulo para que o governo, os parlamentares e o público apoiem essas mudanças. A relevância da questão ambiental para o controle externo naquele país pode ser avaliada pelo fato de que, por decisão parlamentar, todas as auditorias conduzidas pelo Office of the Auditor General devem verificar o desempenho das políticas públicas segundo o critério dos quatro "Es", que em inglês significam economy, efficiency, effectiveness e environment.

Em junho de 2004, em Brasília, a Conferência Internacional de Auditoria Ambiental reuniu mais de 30 países. O TCU é o coordenador do grupo de auditoria ambiental para as Américas e o Caribe.

\section{A estratégia ambiental do TCU}

Desde 1998, quando foi definida sua estratégia de atuação na área ambiental, e cada vez mais, o TCU vem desempenhando um importante papel na avaliação das políticas públicas do governo federal voltadas para essa área. A atuação do Tribunal de Contas da União em relação à questão ambiental é definida pela Portaria $\mathrm{n}^{\circ} 383$, de 05-8-1998 (BRASIL, 2004b), que "aprova a estratégia de atuação para o controle da gestão ambiental, resultante da implementação do Projeto de Desenvolvimento da Fiscalização Ambiental - PDFA". Essa estratégia foi elaborada "com o objetivo de suprir a carência de um adequado controle externo da gestão ambiental em nível de governo" (BRASIL, 2004b). O documento considera a gestão ambiental como "o conjunto das ações que visem à adequada utilização do meio ambiente"; e igualmente trata do ambiente natural e daquele transformado pela ação humana, das ações de controle e proteção do meio ambiente, bem como daquelas relacionadas a atividades que potencial ou efetivamente causem impacto ambiental negativo. No seu artigo $1^{\circ}$ é definida:

I - a forma de atuação adequada;

II - as áreas da gestão governamental a serem priorizadas;

III - a sistemática e as diretrizes a serem observadas para o planejamento tático;

IV - a estrutura operacional adequada; e

V - a sistemática a ser adotada para a obtenção e o desenvolvimento de recursos.

Segundo o artigo $3^{\circ}$, o controle da gestão ambiental pelo TCU será efetuado:

I - pela fiscalização ambiental de:

a) ações executadas por órgãos e entidades do Sistema Nacional de Meio Ambiente (Sisnama);

b) políticas e programas de desenvolvimento que potencial ou efetivamente causem degradação ambiental.

II - pela inclusão do aspecto ambiental na fiscalização de:

a) políticas e programas de desenvolvimento que potencial ou efetivamente causem degradação ambiental; 
b) projetos e atividades que potencial ou efetivamente causem impacto negativo direto ao meio ambiente.

III - pela inclusão do aspecto ambiental no processo de prestação de contas de órgãos e entidades:

a) integrantes do Sisnama;

b) responsáveis pelas políticas, programas, projetos e atividades a que se refere o inciso anterior.

Deve ser ressaltado que o conceito de fiscalização ambiental abrange as auditorias, inspeções, levantamentos e acompanhamentos que tenham por objeto a análise da gestão ambiental.

No documento principal, anexo à portaria, a missão institucional do TCU com respeito ao meio ambiente foi assim definida:

"Exercer, em auxílio ao Congresso Nacional, o controle externo da gestão ambiental de responsabilidade do Governo Federal e dos recursos públicos federais aplicados em atividades relacionadas à proteção do meio ambiente. No exercício de suas atribuições, o Tribunal deve zelar pela legalidade e legitimidade dos atos praticados pelo Governo, bem como pela eficiência, eficácia e economicidade no uso desses recursos e de recursos ambientais."

Bastante relevante é a inclusão, prevista no artigo $3^{\circ}$ e enfatizada no anexo, da avaliação do aspecto ambiental, mesmo em atividades de fiscalização de escopo mais abrangente, isto é, que não digam respeito somente a órgãos, programas, projetos e atividades diretamente relacionados ao meio ambiente. Até a apreciação das contas do presidente da República deve, segundo esse enfoque, ser avaliada considerando-se o desempenho governamental na consecução de suas metas ambientais. Deve se lembrado que, para o Canadá, esse aspecto deve ser verificado em todas as ações do governo. Também na França, há preocupação com o "esverdeamento" da gestão pública (FRANÇA, 1997). Da mesma forma, o grupo permanente de trabalho em auditoria ambiental da Intosai preconiza que as questões ambientais devem ser consideradas em todas as auditorias.

$\mathrm{O}$ artigo $5^{\circ}$ defini como prioritárias as seguintes ações e atividades relacionadas à gestão ambiental:

I - ações que visem induzir comportamentos compatíveis com o modelo de desenvolvimento sustentável;

II - fiscalização ambiental;

III - elaboração e aplicação de políticas setoriais relacionadas à proteção ou utilização do meio ambiente;

IV - ações que visem à coleta e ao fornecimento de informações sobre o meio ambiente;

V - educação ambiental;

VI - coordenação das ações relacionadas à proteção ambiental;

VII - ações implementadas com recursos externos.

Para tanto, é previsto planejamento anual que contemple a fiscalização, o treinamento e outras ações relacionadas ao controle da gestão ambiental, respeitadas as normas estabelecidas para o planejamento das ações a serem executadas pelo tribunal (artigo $6^{\circ}$ ). Deve ser destacado que, na enumeração constante do artigo $5^{0}$ da portaria, as ações indutoras de comportamentos compatíveis com o modelo de desenvolvimento sustentável tiveram precedência sobre a fiscalização ambiental. É enfatizada uma atuação de caráter preventivo. Não obstante, é responsabilidade do tribunal responder às solicitações que lhe forem formuladas pelo Senado 
Federal, pela Câmara dos Deputados e pela Comissão Técnica ou de Inquérito do Congresso, e ainda receber denúncias que lhe forem enviadas por qualquer cidadão, partido político, associação ou sindicato.

As técnicas habitualmente utilizadas no controle externo realizado pelos auditores do tribunal são as recomendadas pelo documento para as auditorias ambientais. O Manual de Auditoria do TCU tem as características das diversas modalidades de auditorias, bem como das inspeções, levantamentos e acompanhamentos (BRASIL, 2004a). A diferença entre as auditorias "convencionais" e a auditoria ambiental, prende-se, nessa visão, apenas ao objeto de análise. Além disso, foi editado em 2001 o Manual de Auditoria Ambiental do Tribunal de Contas da União (BRASIL, 2004c).

\section{Experiência recente}

As diversas auditorias operacionais feitas pelo TCU em instituições e programas governamentais têm resultado em minuciosos diagnósticos e relevantes recomendações por políticas públicas ambientais mais efetivas. Neste artigo, foram selecionados alguns trabalhos do tribunal na área ambiental, no período 2002-04:

- auditoria operacional, tendo como objeto a avaliação do governo federal na gestão dos recursos hídricos. Decisão nº 566/2002 - plenário, de 29-5-2002;

- auditoria no Programa Saneamento Básico, de responsabilidade da Fundação Nacional de Saúde (Funasa). Acórdão nº 309/2003 - plenário, de 2-4-2003;

- auditoria na Agência Nacional do Petróleo (ANP) e no Ibama, para examinar o relacionamento entre os órgãos responsáveis pela indústria petrolífera e os que cuidam do meio ambiente. Acórdão no 787/2003 - plenário, de 2-7-2003;

- auditoria para definir indicadores de gestão ambiental. Acórdão no 516/2003 - plenário, de 14-52003;

- auditoria de natureza operacional no Ibama envolvendo ações governamentais, para proteger o meio ambiente na região amazônica, possibilitando seu desenvolvimento com foco no emprego de técnicas de manejo florestal sustentável. Acórdão nº 424/2004 - plenário, de 14-4-2004;

- auditoria de natureza operacional no Ibama para identificar fatores relevantes na elaboração e avaliação de estudo de impacto ambiental/relatório de impacto ambiental (EIA/Rima). Acórdão no 462/2004 - Plenário, de 28-4-2004;

- auditoria de natureza operacional na Secretaria de Qualidade Ambiental nos Assentamentos Humanos do Ministério do Meio Ambiente (SQA/MMA), para verificar a aplicabilidade da avaliação ambiental estratégica (AAE) pelo governo federal no planejamento de políticas, planos e programas, bem como o licenciamento ambiental de projetos e obras realizadas com recursos federais. Acórdão no 464/2004 - plenário, de 28-4-2004.

Os dois primeiros exemplos representam fiscalizações de programas e políticas. Os dois últimos envolvem avaliações sobre instrumentos específicos de gestão ambiental. Os comentários feitos adiante se baseiam nos relatórios publicados nas atas do TCU, em anexo às deliberações.

A auditoria na área de recursos hídricos atuou no Ibama, na Agência Nacional de Águas (ANA) e no Ministério do Meio Ambiente (MMA), examinando as conseqüências socioeconômicas da redução da disponibilidade hídrica no Brasil, identificando quais estados correm o risco de desabastecimento. Além disso também foram identificadas quais as boas práticas na gestão dos recursos hídricos, que contribuam para solucionar a crise de abastecimento, além dos procedimentos adotados pelas empresas de abastecimento para evitar o desperdício. $\mathrm{O}$ TCU fez determinações aos diversos órgãos/entidades, visando melhorar a gestão desses recursos. Dessas determinações se destacam: 
- a determinação à Secretaria de Gestão do Ministério do Planejamento, Orçamento e Gestão de que:

a) estude a inclusão nos instrumentos contratuais referentes às linhas de crédito que vierem a ser estabelecidas para as companhias de abastecimento, de instrumentos de controle e acompanhamento - por meio de indicadores de desempenho -, vinculando a liberação de novos recursos ao cumprimento das metas e à efetiva redução dos índices de perdas do prestador de serviços;

b) analise a possibilidade dos programas de saneamento passarem a receber a chancela de prioritários com fluxo de recursos, pois esse mecanismo garantirá o desenvolvimento da programação financeira sem interrupções orçamentárias.

- a determinação à Secretaria de Recursos Hídricos do Ministério do Meio Ambiente e à ANA que sinalizem ao Ministério do Planejamento, Orçamento e Gestão e à Presidência da República o grau de prioridade com que a crise de abastecimento de água deve ser tratada;

- a determinação à ANA que:

a) priorize a formulação de um Plano Nacional de Recursos Hídricos, previsto na Lei nº 9.433/97 - que estabeleça critérios claros para a atuação do governo federal na gestão dos recursos hídricos - e identifique áreas prioritárias de atuação, inclusive, no que diz respeito a obras hídricas;

b) priorize a implementação do Sistema Nacional de Informações sobre Recursos Hídricos (SNIRH), para que as instituições desse sistema tenham à sua disposição, o mais rápido possível, as informações necessárias ao desempenho de suas funções; e

c) promova ações e estudos para garantir - pela cobrança pelo uso da água - o devido incentivo à racionalização do seu uso, reconhecendo a água como bem econômico.

- a determinação à Secretaria Especial de Desenvolvimento Urbano da Presidência da República que:

a) estude formas de promover a reabertura de linhas de crédito para o setor de saneamento;

b) priorize ações voltadas à melhoria da gestão institucional, operacional e comercial de todas as companhias de saneamento estaduais, com ênfase nas empresas mais deficitárias sob o aspecto operacional e comercial;

c) estabeleça, sempre que adequado, como critério para que projetos de saneamento - novos sistemas de água e esgoto e ampliação de sistemas antigos - sejam implementados ou financiados pelo governo federal, a obrigação de tratar o esgoto coletado, conforme diretrizes do Decreto Presidencial $\mathrm{n}^{\mathbf{0}}$ 4.024/01 que estabelece critérios de sustentabilidade para a implantação ou o financiamento de obras hídricas com recursos financeiros da União; e

d) priorize ações destinadas à aprovação de projeto de lei que estabeleça diretrizes para a regulação e fiscalização dos serviços de saneamento e de uma política nacional de saneamento.

- a determinação à Secretaria Especial de Desenvolvimento Urbano da Presidência da República e à Secretaria da Receita Federal do Ministério da Fazenda que estudem a viabilidade de se oferecer incentivos fiscais ao setor, reduzindo a carga tributária sobre materiais e equipamentos utilizados pelas companhias de água e esgotos.

As diretrizes estabelecidas pela Tribunal de Contas da União atingem não apenas os órgãos responsáveis pelas políticas de recursos hídricos e de saneamento, mas também a área econômica do governo federal. Na fiscalização relacionada ao programa Saneamento Básico, sob responsabilidade da Funasa, o TCU determinou àquela entidade, entre outras coisas, que: 
- opte, sempre que possível, pela concepção de sistemas integrados, prevendo desde a captação da água até o tratamento dos esgotos, para minimizar o impacto ambiental causado pela falta de tratamento de efluentes;

- acompanhe a evolução de indicadores de morbidade e mortalidade, principalmente as taxas de internação hospitalar por doença diarréica aguda em menores de cinco anos e por esquistossomose em áreas endêmicas, procurando mensurar o impacto causado pelas ações do Programa Saneamento Básico nos indicadores de saúde;

- promova o fortalecimento da figura do agente municipal de saneamento, através da intensificação do programa de capacitação e da realização de atividades de conscientização dos prefeitos quanto à importância do papel desse agente;

- estimule o envolvimento de associações comunitárias e dos conselhos municipais de saúde no gerenciamento das ações de saneamento, por meio da inclusão, nos projetos de saneamento, de ações de sustentabilidade que contemplem a participação da comunidade, conforme as condições específicas para o financiamento dos projetos; e

- institua indicadores de desempenho, para fazer o acompanhamento e a avaliação gerencial do Programa Saneamento Básico.

Nesse trabalho, o TCU constatou diversas falhas na gestão do programa. Suas determinações alcançaram aspectos técnicos da concepção de projetos, do controle de desempenho mediante indicadores e do controle social com a participação das comunidades. $\mathrm{Na}$ auditoria que examinou o relacionamento entre os órgãos envolvidos com a indústria do petróleo e os órgãos responsáveis pelo meio ambiente, foi constatada a falta de integração entre os setores energético e ambiental na formulação das políticas públicas e de planejamento, no âmbito regulatório e executivo, e a carência de pessoal no Ibama para concessão de licença ambiental. Das principais determinações, cabe destacar:

- a de que o Ibama verifique o cumprimento dos condicionantes do licenciamento ambiental e garanta estrutura adequada, de pessoal e material, à fiscalização das atividades da indústria petrolífera em todo território nacional;

- que a ANP adote sistemas integrados de fiscalização com os órgãos ambientais, para compartilhar informações e ações relativas à fiscalização da segurança operacional e da qualidade ambiental;

- a de que o ministro de Minas e Energia, na qualidade de presidente do Conselho Nacional de Política Energética (CNPE), incentive a avaliação ambiental estratégica como instrumento para balizar a formulação da política energética nacional e o planejamento da expansão da indústria petrolífera; e

- ao CNPE, Conselho Nacional do Meio Ambiente (Conama), Ministério de Minas e Energia, Ministério do Meio Ambiente, ANP e ao Ibama a adoção de mecanismos de cooperação consistentes e sistemáticos que possibilitem formular uma política energética e ambiental.

Nessa auditoria foi verificada a necessidade de maior cooperação e sinergia entre os diversos órgãos governamentais. Pela primeira vez, também se cuidou da avaliação ambiental estratégica, objeto de trabalho específico que será comentado adiante. Quanto à auditoria realizada para definir indicadores de gestão ambiental, os órgãos fiscalizados foram: Ministério de Minas e Energia, Ministério da Integração Nacional, Ministério do Meio Ambiente, Ministério dos Transportes, Departamento Nacional de Infra-estrutura de Transportes (DNIT), Companhia de Desenvolvimento dos Vales do São Francisco e do Parnaíba (Codevasf) e o Ibama. Quanto às principais determinações do TCU, foram:

- determinar ao Ibama que faça constar, na prestação de contas anual da entidade, os seguintes indicadores: 
a) número de licenças ambientais concedidas após o prazo máximo destinado à sua análise que estejam em desacordo com a legislação;

b) número de empreendimentos licenciados pelo Ibama anualmente; e

c) empreendimentos vinculados a órgãos e entidades federais que foram multados, receberam autos de infração, foram embargados ou que tenham recebidos outras punições aplicadas pelo Ibama, por descumprimento das normas de licenciamento ambiental, discriminando qual a penalidade aplicada e o valor total das multas.

- determinar à sua área técnica que em futuras auditorias de obras sejam consideradas como "irregularidade grave", as seguintes ocorrências:

a) contratação de obras com base em projeto elaborado sem licença prévia; e

b) início de obras sem licença de instalação, bem como o início das operações do empreendimento sem a licença de operação com base nas resoluções do Conama nº 237/97 e n-06/87.

Essas determinações são extremamente importantes. De um lado, procura-se estabelecer critérios objetivos para aferir a eficácia e a tempestividade da gestão ambiental. De outro, a conceituação de irregularidade grave quando do inadequado licenciamento ambiental de obras realizadas com recursos públicos federais pode levar a sanções previstas nas Leis de Diretrizes Orçamentárias (LDOs), tais como o bloqueio de repasses orçamentários e a paralisação das obras.

$\mathrm{Na}$ auditoria de natureza operacional com foco em ações governamentais - eficaz na proteção ao meio ambiente na região amazônica, possibilitando seu desenvolvimento -, o objetivo foi estudar experiências de

"emprego de técnicas de manejo florestal sustentável na Amazônia, identificando as ações que obtiveram êxito em promover o desenvolvimento sustentável da região e que poderiam ser apoiadas e adotadas pelo governo federal, bem como apresentar recomendações para melhoria do desempenho da atuação governamental na proteção ambiental”.

O termo "sustentável" foi compreendido como "ambientalmente correto, socialmente justo e economicamente viável". Nas conclusões, o TCU recomendou:

- ao Ibama que:

a) adote medidas para desburocratizar o processo de aprovação dos planos de manejo florestal, para incentivar o setor madeireiro a adotar as práticas sustentáveis; e

b) estude a viabilidade de aplicação de mecanismos econômicos para equiparar a competição entre a madeira explorada com base em planos de manejo e a proveniente de desmatamento legal.

- às secretarias de Biodiversidade e Floresta (MMA), de Coordenação da Amazônia (MMA), de Desenvolvimento Sustentável (MMA) e ao Instituto Nacional de Colonização e Reforma Agrária (Incra), que providenciem o macrozoneamento da Amazônia legal com o objetivo de identificar as regiões propícias à exploração florestal - bem como as terras pública protegidas, devolutas ou sem titularidade e as áreas privadas - para nortear as políticas florestais na região;

- à Secretaria de Logística e Tecnologia da Informação do Ministério do Planejamento, Orçamento e Gestão e ao Ibama que estudem formas de normatizar a obrigatoriedade de se verificar a origem da matéria-prima - especialmente, quanto à legalidade na extração -, sempre que os órgãos e entes públicos federais adquirirem produtos que tenham madeira em sua composição. 
A auditoria identificou a importância do manejo sustentável, constatando porém a necessidade de incentivá-lo através de medidas de simplificação administrativa e de mecanismos econômicos.

A seguinte auditoria de natureza operacional no Ibama teve como objetivo avaliar o estudo de impacto ambiental/relatório de impacto ambiental, inclusive identificando os elementos responsáveis pela baixa adesão do empreendedor público ao licenciamento ambiental e as possíveis ações que ampliassem essa adesão. Para isso, foram formuladas três questões:

- quais as principais causas da resistência do empreendedor público ao processo de avaliação do impacto ambiental?

- como as orientações referentes ao processo de avaliação do impacto ambiental são formuladas aos empreendedores públicos?

- como é monitorada a implementação de medidas atenuantes e compensatórias, tidas como necessárias no estudo de impacto ambiental?

Ao finalizar a execução da auditoria, a equipe concluiu que:

- a insuficiência de recursos do Ibama, o fato dos empreendedores não terem a expectativa do controle e o baixo custo da irregularidade comparado ao custo da legalidade contribuem para a baixa adesão do empreendedor público ao licenciamento ambiental;

- Ibama não tem uma atuação efetiva na detecção das irregularidade, para que possa punir os empreendedores inadimplentes; e

- Ibama não vem monitorando sistematicamente a implementação dos condicionantes das licenças ambientais por ele expedidas.

O relatório de auditoria constatou que:

"Em termos gerais pode-se resumir a situação da seguinte forma: o empreendedor está em situação irregular, mas não tem a expectativa de que o poder coercitivo do Estado irá atingi-lo; por outro lado o IBAMA detém o poder de coerção mas não o exerce, por absoluta falta de recursos materiais e humanos."

Das determinações do TCU ao Ibama, destacam-se:

- a de que realize estudos sobre o custo acarretado pelo contingenciamento de seus recursos próprios, determinado pelos Ministérios do Planejamento e da Fazenda, de modo a subsidiar a solicitação, junto aos mesmos, de seu descontingenciamento, solicitação essa que deverá ser acompanhada de levantamento devidamente fundamentado das necessidades do instituto a serem atendidas com o incremento pretendido;

- a de que sejam revistos os critérios de fixação dos valores das taxas do licenciamento em relação ao custo total do empreendimento, visando estabelecer o equilíbrio entre os valores, sem prejuízo da obrigação de ressarcimento do dano ambiental decorrente do empreendimento; e

- a de que adote medidas para evitar que os processos de regularização (promovidos a posteriori) sejam mais atrativos que o processo normal de licenciamento (promovido previamente);

É importante acrescentar que com a consolidação dos dados relativos a fiscalizações de obras em 2003, verificou-se que das 214 obras fiscalizadas que exigiam licença ambiental, 33,6\% não tinham essa licença. Em relação à implementação das medidas mitigadoras definidas nas licenças de 163 obras fiscalizadas, 42,3\% dessas obras não as implementaram. Dessa forma, podemos concluir que do total de 214 obras que exigiam licença ambiental, 141 obras, ou 66\% desse total, não cumpriam a legislação. 
Além disso, a auditoria de natureza operacional na Secretaria de Qualidade Ambiental nos Assentamentos Humanos (SQA/MMA) procurou analisar a aplicabilidade, pelo governo federal, da avaliação ambiental estratégica (AAE) nas ações de planejamento de políticas, planos e programas, bem como o licenciamento ambiental de projetos e obras realizadas com recursos federais. Foi identificado o papel potencialmente positivo do instrumento como indutor de boas práticas, em particular para superar as deficiências identificadas no estudo de impacto ambiental, e também as falhas no cumprimento de normas ambientais em obras realizadas com recursos federais. A deliberação do TCU incluiu as seguintes recomendações:

- à Secretaria de Qualidade Ambiental nos Assentamentos Humanos do Ministério do Meio Ambiente que amplie a divulgação da avaliação ambiental estratégica e a oferta de capacitação sobre o tema aos demais órgãos e entidades governamentais;

- à Secretaria de Planejamento e Investimentos Estratégicos do Ministério do Planejamento e Orçamento que analise a conveniência de adotar a avaliação ambiental estratégica na elaboração do Plano Plurianual; e

- à Secretaria Executiva da Casa Civil que analise a conveniência de passar a orientar os órgãos e entidades federais que causam impacto ambiental significativo, para que apliquem a avaliação ambiental estratégica no planejamento de políticas, planos e programas setoriais.

Nessa fiscalização, o TCU demostrou sintonia com um instrumento de gestão ambiental relativamente recente e pouco conhecido, além de não regulamentado legalmente. Ao examinar a aplicabilidade da avaliação ambiental estratégica e recomendar sua divulgação e utilização, o tribunal assumiu uma posição de vanguarda na gestão ambiental pública em nosso país. Além do mais, tendo mais uma vez constatado os problemas relativos ao processo de licenciamento ambiental, o TCU publicou a Cartilha de Licenciamento Ambiental (BRASIL, 2004d), para a orientação de gestores, empreendedores, legisladores e ativistas de organizações nãogovernamentais.

\section{Conclusão}

Os exemplos da atuação ambiental do TCU nos últimos dois anos descritos neste artigo revelam o esforço por um controle preventivo, pedagógico e orientador da gestão pública, que substitua o tradicional modelo de controle formalista e a posteriori. Verifica-se uma atuação abrangente que diagnostica problemas estruturais e define determinações, inclusive, para a área econômica do governo federal, onde freqüentemente estão os "gargalos" ou "garrotes" da administração pública. Há uma clara preocupação não apenas com os aspectos da legalidade, mas também com a eficiência dos instrumentos da política ambiental. Em síntese, pode-se avaliar a atuação ambiental do Tribunal de Contas da União como bastante positiva para a sociedade, recomendando-se a sua ampliação, voltando-se inclusive para temas como as mudanças climáticas, o desenvolvimento da contabilidade ambiental e o projeto de transposição do rio São Francisco. 


\section{Referências bibliográficas}

BANDEIRA DE MELLO, C. A. Curso de direito administrativo. 9. ed. rev., atual. e aum. São Paulo: Malheiros Editores, 1997.

BRASIL. Constituição (1988). Constituição da República Federativa do Brasil. Brasilia, DF: Senado, 1988.

BRASIL. Ministério do Meio Ambiente, dos Recursos Hídricos e da Amazônia Legal. Primeiro Relatório Nacional para a Convenção sobre Biodiversidade Biológica: Brasil. Brasilia, DF: Ministério do Meio Ambiente, dos Recursos Hídricos e da Amazônia Legal. 1998.

BRASIL. Tribunal de Contas da União. Portaria no 63, de 27 de fevereiro de 1996. Aprova o Manual de auditoria do TCU. Brasília, DF. Disponivel em: <www.tcu.gov.br>. Acesso em: 19 ago. 2004a.

Tribunal de Contas da União. Portaria no 383, de 05 de agosto de 1998. "Aprova a estratégia de atuação para o controle da gestão ambiental, resultante da implementação do Projeto de Desenvolvimento da Fiscalização Ambiental - PDFA". Brasilia, DF. Disponível em: <www.tcu.gov.br>. Acesso em: 19 ago. $2004 b$.

. Tribunal de Contas da União. Boletim do TCU no 52, de 16 de junho de 2001. Edição especial Manual de Auditoria Ambiental do Tribunal de Contas da União. Brasilia, DF. Disponivel em: <www.tcu.gov.br>. Acesso em: 19 ago. 2004c.

. Tribunal de Contas da União. Cartilha de Licenciamento Ambiental. Brasilia, DF. 2004. Disponivel em: <www.tcu.gov.br>. Acesso em: 19 ago. 2004d.

FRANÇA. Ministère de L'Environnement. Le verdissement de l'administration. Paris: Ministère de l'Environnement, 1997.

GLIGO, N. Institucionalidad publica y políticas ambientales explícitas y implícitas. Revista de la Cepal, Santiago, n. 63, p.51-63, dic. 1997.

INTOSAI - International Organisation of Supreme Audit Institutions. The Lima Declaration of Guidelines on Auditing Precepts. Vienna: Intosai, 1977.

How SAls may co-operate on the audit of international environmental accords. Vienna: Intosai, 1998.

LIMA, L. H. Controle do patrimônio ambiental brasileiro: a contabilidade como condição para o desenvolvimento sustentável. Rio de Janeiro: Uerj, 2001.

SANTOS, H. Comunicações da Presidência - Fiscalização ambiental no âmbito do TCU. União, Brasilia, DF, p.1, 28 ago.1997. 